\title{
Maximum phonation times and vital capacity in dysphonic women
}

\author{
Aline Costa Leite ${ }^{(1)}$ \\ Mara Keli Christmann (2) \\ Carla Franco Hoffmann ${ }^{(1)}$ \\ Carla Aparecida Cielo(1)
}

1) Universidade Federal de Santa Maria, Santa Maria, Rio Grande do Sul, Brasil.

2) Associação Educacional Luterana Bom Jesus, Joinville, Santa Catarina, Brasil. Research support source: CNPq

Conflict of interests: Nonexistent

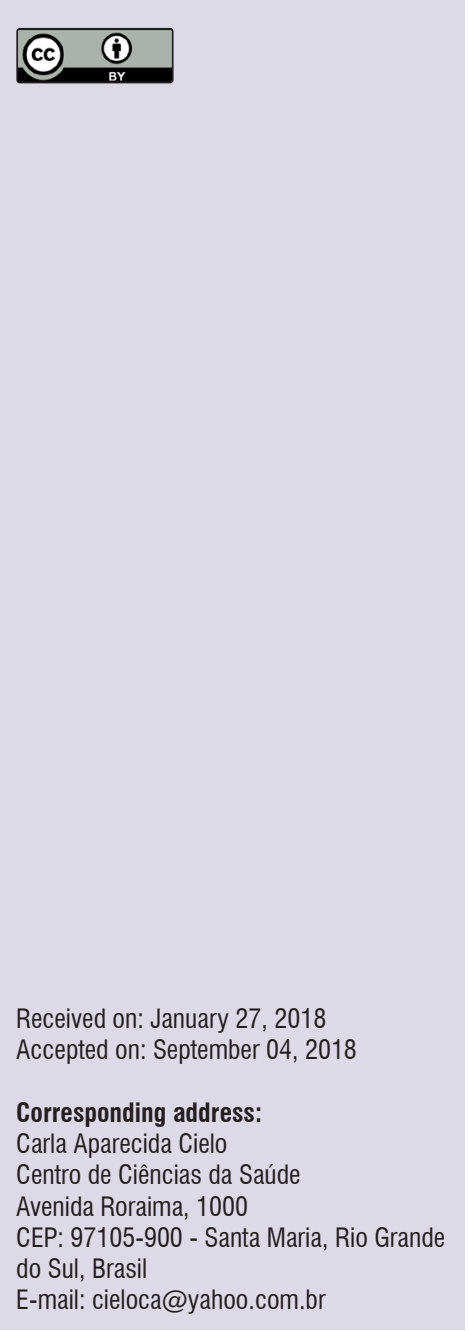

\section{ABSTRACT}

Objective: to verify the correlation between vital capacity and maximum phonation times of /é/ (unvoiced) and /s/, as well as compare and relate them with the professional voice use and age in women with functional or organic-functional dysphonia.

Methods: a retrospective research with 524 records of dysphonic patients from a school clinic, including young adult women with a speech-language diagnosis of functional or organic-functional dysphonia based on medical reports. Neurological and psychiatric alterations, previous speech therapy treatment, symptoms of flu or allergies on the day of evaluation, pulmonary disease, organic dysphonia diagnosis, and hearing loss, were excluded. The sample resulted in 14 women with functional dysphonia and 21 with organic-functional dysphonia. Data on professional voice use, as well as results for vital capacity and maximum phonation times were collected. The data were statistically analyzed at a $5 \%$ significance level.

Results: There was a positive correlation for both groups of dysphonic patients between the maximum phonation times of /eे/ and of /s/, as well as the maximum phonation times of $/ \dot{\mathrm{e}} /, / \mathrm{s} /$, and vital capacity. Higher values for vital capacity and maximum times of $/ \mathrm{s} /$ and /è/ for voice professionals were seen. The maximum phonation times of /ë/ were lower than those of $/ \mathrm{s} /$.

Conclusion: as the maximum phonation times of /è/ increased, the maximum phonation times of /s/ and the vital capacity also augmented in both groups, demonstrating the interrelation among these variables; there was no relation with the other variables studied.

Keywords: Voice; Phonation; Vital Capacity; Voice Disorders 


\section{INTRODUCTION}

The respiratory system has a vital role for the proper production of voice, since the expiration of air works as the activating source of emission. Aerodynamic measures of vocal emission are one of the dimensions of vocal evaluation. They expose the control conditions of the respiratory forces and the glottic efficiency, as well as the compensatory vocal behaviors of individuals, especially those with vocal disorders ${ }^{1-3}$. Among these measures, some standardized stand out such as Vital Capacity (VC) and the Maximum Phonation Times (MPT), which aid the identification of voice alterations for the individual ${ }^{2,4-6}$.

VC refers to the maximum expiration that the individual can perform after a maximum inspiration ${ }^{3,5-10}$. Results may vary according to stature, age, gender, proper health conditions, physical training, alcohol or smoking habits, and professional voice use. The values found vary from $2,100 \mathrm{ml}$ to $3,300 \mathrm{ml}$ for women, and $2,200 \mathrm{ml}$ to $4,000 \mathrm{ml}$ for $\mathrm{men}^{5,6,9}$. The VC may influence the MPT despite not determining it, given that both measures depend on the airflow control coming from the lungs ${ }^{6,7,9,11}$.

The MPT is obtained through the sustained emission of vowels, fricatives, and/or counting of numbers during a prolonged expiration, in normal pitch and loudness. Besides helping to describe vocal behavior, it is used to verify how the patient controls the aerodynamic forces of the expiratory air current and the myoelastic forces of the larynn $x^{2,4,6-8,12-15}$. It allows characterizing the glottic source regarding its muscular and muco-undulatory functioning and its vocal quality, seeing that some alterations are better observed in the sustained emission of isolated phonemes ${ }^{6,8,16}$.

MPT may be measured, among others, using the fricative phoneme $/ \mathrm{s} /$ and the sustaining of the voiceless /e/ (/è/), both unvoiced emissions. MPT/s/ measures the respiratory control for not having vibrations of the vocal folds ${ }^{12,13}$ but suffers articulatory influence because it presents a constriction at the alveolar articulatory level $^{3,17}$. The production of the MPT /è/ seems to be more reliable to analyze blow control through exclusive respiratory support, evaluating the control of the respiratory musculature in the sustaining of the expiratory air column during a voiceless emission ${ }^{3,5,16}$.

The unvoiced MPTs are important given that, during phonation, the balance and control of respiratory forces are essential. Therefore, its use in the evaluation of all types of dysphonia and voice professionals is emphasized. Such measures are necessary to verify the performance of the respiratory level ${ }^{1-6}$ since it needs to be balanced with the with the other vocal production levels so as not to generate pneumo-phono-articulatory incoordination ${ }^{3,6}$. If the aerodynamic forces are not in accordance with the vocal demands, such as with voice professionals, it can lead to hyperfunction behaviors generating tension to the phonation, brusque vocal attacks, fatigue, and dysphonias ${ }^{6}$. Such aspects, in turn, may lead to the emergence of functional laryngeal unbalances and organic-functional lesions.

Voice alterations due to structural laryngeal affections on the vocal folds, caused by the incorrect use of the voice, are called organic-functional dysphonias (OFD) $4,7,11,14,17$.

On the other hand, functional dysphonia (FD), although not consensual, consists of a behavioral voice problem in the absence of organic, neurological, or psychological etiology ${ }^{18}$. It presents predisposing factors such as genetic susceptibility, psychological issues, and, chiefly, the vocal behavior that may be compromised in voice professionals who are unaware of vocal health care $^{18}$.

The female gender may present lower MPT and VC values compared to the male gender ${ }^{6}$. Voice professionals may present the same VC values of individuals who do not use their voice professionally ${ }^{6}$. As for the MPT, in a study with voice professionals, teachers, discretely larger MPT values compared to the control group were observed ${ }^{19}$, with a similar result being found in a longitudinal study with teachers who presented larger MPT values when compared to people who were not voice professionals ${ }^{20}$. In another study with Iranian teachers, the opposite result was found: the study group presented lower MPT values, a finding attributed to the pneumo-phono-articulatory incoordination of the teacher group ${ }^{21}$.

Despite the measures approached in this work being widely used in clinical practice, scientific studies relating them to each other are scarce. Correlating VC and unvoiced MPT values may contribute to enlighten whether VC is sufficient in sustaining the unvoiced MPT, seeing that it depends on the pulmonary air volume $^{1-3}$. That is, besides a normal VC, it would also be necessary to have a proper expiratory muscle control to sustain the unvoiced MPT ${ }^{1-3,5,6,7,9,11,16}$. These results would reverberate in the objectives of the speech therapy treatment for behavioral dysphonias (FD and OFD), in which pneumo-phono-articulatory incoordination is often observed ${ }^{3,6}$. The same occurs regarding individuals who are voice professionals and need 
adequate pneumo-phono-articulatory coordination ${ }^{18}$ to avoid overcharging one of the voice production levels - usually the glottic or phonatory level -, possibly developing laryngeal organic-functional lesions $\mathrm{s}^{4,7,11,14,17}$.

Considering the exposed, this study had the purpose of verifying the correlation among VC, MPT/e/ (unvoiced), and MPT/s/, as well as compare and relate them with the professional voice use and the age of women with FD or OFD.

\section{METHODS}

\section{Ethical Aspects}

An analytical, observational, cross-sectional, quantitative, and retrospective study using a database of patients attended at the voice sector of a speech therapy school clinic.

This study was approved by the Research Ethics Committee (REC) of the Universidade Federal de Santa Maria - UFSM (no. 56444616.0.0000.5346), with all subjects signing the Term that authorizes the use of data from the medical charts at the school clinic.

\section{Inclusion criteria}

To compose the sample, we considered as inclusion criteria the following information from the database: adherence to the term of medical chart data usage; female gender; adult age range (19 to 44 years of age) to discard alterations due to the vocal change period and to the influence of hormonal and structural alternations due to aging ${ }^{6,7,17}$; speech-language diagnosis of FD or OFD based on the otorhinolaryngologist's report; data on the professional voice use and measures of VC and MPT for $/ \mathrm{s} /$ and $/ \dot{\mathrm{e}} /$.

\section{Exclusion criteria}

We excluded from the study: a record of the report or diagnosis of neurological or psychiatric alterations ${ }^{3,5}$; a record of speech therapy treatment before the evaluation date ${ }^{3,6,16}$; having symptoms of flu or allergies on the day of evaluation ${ }^{5}$ report or diagnosis of pulmonary disease ${ }^{5,7}$; diagnosis of organic dysphonia; and diagnosis of hearing loss ${ }^{5,7}$.

The database had a total of 524 tabulated records of patients. After applying the inclusion and exclusion criteria, the sample was constituted by 35 women. The mean ages were of 28.4 years in the FD group $(n=14)$ and 27.3 years in the OFD group $(n=21)$. The women who were voice professionals were two choralists, four teachers, and one community health agent $(n=7)$, while 28 were not voice professionals.

\section{Data collection}

When coming to the school clinic in the initial collection of the MPT/e/ and MPT/s/ values, the patients were in orthostatic position and sustained the emissions during a prolonged expiration in their usual loudness. At the emission of the MPT/e//, the patients were instructed to emit the /é/ without vocalization and any noise whatsoever, maintaining the same articulatory posture of the $/ \mathrm{e} / \mathrm{vowe}^{3,5,16}$ and sustaining the air as if it were a "very light breath"16.

The MPT/e/ and MPT/s/ measures were timed with a digital chronometer in seconds thrice, and we selected the highest value obtained for each measure $3,5,5,22,23$.

Due to the lack of studies about the MPT/è/, as a normality standard, we considered the interval from $10.43^{5}$ to $18 \mathrm{~s}^{3}$, while for MPT/s/ the range was from 15 to $25 \mathrm{~s}^{3,6}$. MPT/e/ and MPT/s/ values below the normality standard were considered suggestive of compromised expiratory control to phonation ${ }^{5}$, while values above the normality were considered better than expected relative to the expiratory control to phonation.

We measured the VC using a dry Fami-Itá ${ }^{\circledR}$ spirometer and registered the results in milliliters $(\mathrm{ml})$. The patients were guided to do a deep inspiration followed by a maximum expiration on the mouth of the spirometer's tube, kept at the same height as the patient's mouth. We considered the largest value among three readings with nasal occlusion and three readings without nasal occlusion ${ }^{5,8}$.

As the normality standard for VC for women, we adopted values from 2,100 $\mathrm{ml}$ up 5,6,8. We considered lower values suggestive of respiratory compromise, possibly making sustaining phonation difficult5,6,8.

The measures were collected by different evaluators who followed the above description. The data on the professional voice use was obtained through the record of the interview/anamnesis with the patient.

All patients were evaluated by an otorhinolaryngologist at the school clinic or private physician, with the medical report attached to the patient's chart. The speech-language diagnosis of the type of dysphonia was reached based on the otorhinolaryngologist's report 6 . We considered as OFD the presence of vocal nodules, polyps, edema, and thickening of the vocal folds, and as FD the minimal structural alteration of the coverage, glottic clefts, and incorrect vocal habits. 


\section{Data analysis}

The data was tabulated, descriptively analyzed, and submitted to the statistical analysis through the statistical tests of Pearson Correlation, ANOVA to compare among the variables, and Chi-Squared to verify the relation among the qualitative data. We adopted the $5 \%$ significance level $(p \leq 0.05)$. In the statistical analysis, we used the SPSS V17, Minitab 16, and Excel Office 2010 software.

\section{RESULTS}

Considering MPT /è/, we found a mean of 12.1 $\mathrm{s}$ for the FD group and $10.7 \mathrm{~s}$ for the OFD group. For the MPT /s/, the means were of 14.9 and $13.6 \mathrm{~s}$, respectively. The average VC values for the FD and OFD groups were, respectively, of 3,157 and 2,986 ml, thus within the normality standards. The majority of the sample was of subjects who were not voice professionals $(80 \%)$.

The statistical results are exposed in Tables 1, 2 , and 3. Table 1 shows the descriptive analysis of variables age, VC, MPT /è/, and MPT /s/ for each group and the whole sample, presenting the mean, standard deviation, and minimum and maximum values of such variables.

Table 2 shows the correlation among MPT /è/, MPT $/ \mathrm{s} /$, and VC, with all variables presenting a positive correlation.

Table 1. Descriptive analysis of variables age, maximum phonation times of /è/ and $/ \mathrm{s} /$, and vital capacity

\begin{tabular}{ccccccc}
\hline \multicolumn{2}{c}{ Descriptive } & Mean & SD & Min. & Max. & n \\
\hline \multirow{3}{*}{ Age (years) } & Total & 27.7 & 8.4 & 19 & 44 & 35 \\
& OFD & 27.3 & 8 & 19 & 44 & 21 \\
& FD & 28.4 & 9.2 & 19 & 44 & 14 \\
\hline \multirow{3}{*}{ MPT/ $\square /(s)$} & Total & 11.3 & 7.7 & 1.1 & 37.5 & 35 \\
& OFD & 10.7 & 7.1 & 1.1 & 36 & 21 \\
& FD & 12.1 & 8.7 & 2 & 37.5 & 14 \\
\hline \multirow{3}{*}{ MPT/s/ (s) } & Total & 14.2 & 7.5 & 3 & 34.12 & 35 \\
& OFD & 13.6 & 7 & 5.9 & 34.1 & 21 \\
& FD & 14.9 & 8.4 & 3 & 31.7 & 14 \\
\hline \multirow{2}{*}{ VC (ml) } & Total & 3,054 & 638 & 1,000 & 4,500 & 35 \\
& OFD & 2,986 & 407 & 2,500 & 3,800 & 21 \\
& FD & 3,157 & 890 & 1,000 & 4,500 & 14 \\
\hline
\end{tabular}

Caption: MPT/è/=maximum phonation time of $/ \dot{\mathrm{e}} / ; \mathrm{MPT} / \mathrm{s} /=$ maximum phonation time of $/ \mathrm{s} / ; \mathrm{VC}=$ vital capacity; $\mathrm{SD}=$ standard deviation; $\mathrm{n}=$ sample size; $\mathrm{FD}=$ functional dysphonia; $\mathrm{OFD}=$ organic-functional dysphonia; $\mathrm{s}=$ seconds; $\mathrm{ml}=$ milliliters.

Table 2. Correlation of variables maximum phonation times of /è/ and /s/, and vital capacity in the whole sample

\begin{tabular}{ccc}
\hline & Corr $(\mathbf{r})$ & p-value \\
\hline $\mathrm{MPT} / \dot{\mathrm{e}} /$ e MPT/s/ & $59.10 \%$ & $<0.001^{*}$ \\
$\mathrm{MPT} / \dot{\mathrm{e} /}$ e VC & $43.10 \%$ & $0.010^{\star}$ \\
$\mathrm{MPT} / \mathrm{s} /$ e VC & $55.50 \%$ & $0.001^{*}$ \\
\hline
\end{tabular}

Caption: $\mathrm{MPT} / \mathrm{e} /=$ maximum phonation time of $/ \square / \mathrm{MPT} / \mathrm{s} /=$ maximum phonation time of $/ \mathrm{s} / ; \mathrm{VC}=$ vital capacity. 
Table 3 shows the comparison among variables age, professional voice use, and speech-language diagnosis with MPT /è/, MPT /s/, and VC, presenting their mean, standard deviation, and p-value. The variables did not show significant results.

Table 3. Comparison of the variables professional voice use and speech-language diagnosis relative to age, maximum phonation times of /è/ and /s/, and vital capacity

\begin{tabular}{|c|c|c|c|c|c|}
\hline & & Mean & SD & $n$ & p-value \\
\hline \multicolumn{6}{|c|}{ Professional Voice Use } \\
\hline \multirow{2}{*}{ Age (years) } & No & 27.6 & 8.6 & 28 & 0.85 \\
\hline & Yes & 28.3 & 8.1 & 7 & \\
\hline \multirow[t]{2}{*}{ MPT/è/ (s) } & No & 10.2 & 6.8 & 28 & 0.11 \\
\hline & Yes & 15.4 & 9.8 & 7 & \\
\hline \multirow[t]{2}{*}{ MPT/s/ (s) } & No & 13.8 & 7.9 & 28 & 0.59 \\
\hline & Yes & 15.5 & 5.8 & 7 & \\
\hline \multirow[t]{2}{*}{ VC (ml) } & No & 3,018 & 676 & 28 & 0.50 \\
\hline & Yes & 3,200 & 473 & 7 & \\
\hline \multicolumn{6}{|c|}{ Speech-Language Diagnosis } \\
\hline \multirow[t]{2}{*}{ Age (years) } & $\mathrm{FD}$ & 28.4 & 9.2 & 14 & 0.7 \\
\hline & OFD & 27.3 & 8 & 21 & \\
\hline \multirow[t]{2}{*}{ MPT/è/ (s) } & FD & 12.1 & 8.7 & 14 & 0.59 \\
\hline & OFD & 10.7 & 7.1 & 21 & \\
\hline \multirow[t]{2}{*}{ MPT/s/ (s) } & FD & 14.9 & 8.4 & 14 & 0.61 \\
\hline & OFD & 13.6 & 7 & 21 & \\
\hline \multirow[t]{2}{*}{$\mathrm{VC}(\mathrm{ml})$} & FD & 3,157 & 890 & 14 & 0.44 \\
\hline & OFD & 2,986 & 407 & 21 & \\
\hline
\end{tabular}

Caption: MPT/è/=maximum phonation time of /è/; MPT/s/=maximum phonation time of /s/; VC=vital capacity; $\mathrm{SD}=$ standard deviation; $\mathrm{n}=$ sample size; $\mathrm{FD}=$ functional dysphonia; $\mathrm{OFD}=$ organic-functional dysphonia; $\mathrm{s}=$ seconds; $\mathrm{ml}=$ milliliters .

ANOVA Test.

\section{DISCUSSION}

There was a significant positive correlation between MPT/e/ and MPT/s/ for both groups analyzed (Table 2). This positive correlation was also found in a study that compared these variables and stature in a group of adult women with normal voices ${ }^{24}$. Both measures evaluate the respiratory muscle control in sustaining the expiratory air column during a voiceless emission and, therefore, this result was expected.

The results also showed a significant positive correlation between MPT /è/ and MPT /s/ and the VC for both groups analyzed (Table 2). This demonstrates the influence of VC values over the MPT /s/ and MPT /è/, that is, the higher the VC, the higher the unvoiced MPT tends to be, seeing that both measures depend on the control of the airflow from the lungs, agreeing with the literature ${ }^{3,6-8,11,13}$. For this reason, these variables are used to describe pneumophonic coordination.
According to the literature ${ }^{3}$, the normality of the MPT/e/ may vary from 16 to $18 \mathrm{~s}$. However, a field study with adult women with normal voices ${ }^{5}$ found average MPT /è/ values of $10.43 \mathrm{~s}$. In this study, the average MPT/è/ values found for both groups studied were below the values preconized by the literature ${ }^{3}$, yet within the normality standard adopted from the field study ${ }^{5}$. The results agree with another study ${ }^{16}$ which verified MPT/è/ measurements within the same normality interval we adopted ${ }^{5}$.

It should be noted there are few studies found in the literature $\mathrm{e}^{5,16,24,25}$ about the MPT /e//, and that its normality values are still not established given the vast disparity of findings ${ }^{3,5,16}$. Thus, one may notice the need to deepen the scientific researches on the MPT /è/.

Regarding subjects without laryngeal affections, one may find normality values for the MPT/s/ from 15 to $25 \mathrm{~s}$ for women ${ }^{5,6,15,16}$, differently from what was 
found for the FD and OFD groups in this study. The FD group included some laryngeal affections (medical report of minimal structural alteration of the coverage or glottic crevices), and the OFD group also presented laryngeal affections. The decreased MPT/s/ values in these groups are similar to those of studies ${ }^{7,17,23,26}$ which compared the MPTs of vowels and fricatives in subjects with laryngeal affections, finding reduced MPT /s/ values for women.

The MPT results are related with the glottic closing and with the respiratory control. The higher the MPT value, the better the glottic or respiratory control. The MPT/s/ is unvoiced and does not depend on the glottic control; its sustaining time is controlled by the respiratory ${ }^{5-7,16,24}$ and articulatory ${ }^{3,17}$ levels. Hence, one cannot attribute the reduction of MPT /s/ or MPT /eे/ to the laryngeal affections of this study's FD and OFD groups.

A study ${ }^{19}$ that analyzed the effects of voice therapy in 21 dysphonic subjects of both genders found pre-therapy MPT /s/ values of $17.05 \mathrm{~s}$, within normality, thus diverging from the MPT /s/ results of this study.

The literature mentions that MPT values may vary according to age, such as with elders, in which the reduction of this measure is due to laryngeal and pulmonary modifications due to aging ${ }^{3,6,12}$. However, in this study, there was no significant correlation among MPT, VC, and age, probably due to the chosen age range having excluded women over 44 years old. In this study, the average VC of the FD and OFD groups presented itself within the standards found in other studies with adult women $n^{1,2,5,7,15,27,28}$.

There was no significance regarding the VC, MPT /s/, and MPT /è/ measures and age among voice professionals when compared to the group that did not use their voice professionally, neither when compared to the FD and OFD groups (Table 3). The results were similar to the study with voice professionals ${ }^{26}$ which compared the MPT of teachers and non-teachers and found reduced values in both groups.

It is known that VC may be normal in dysphonic subjects $^{3,6}$, as occurred in this study. However, the pneumo-phono-articulatory incoordination expected in dysphonias ${ }^{3,6,18}$ may have influenced the reduction of the unvoiced MPT values in all groups (professional use and diagnosis), keeping in mind that both voice professionals and non-voice professionals presented dysphonia. Still, there are studies about subjects of both genders with OFD ${ }^{17,27}$ that verified a reduction in MPT and VC, partially converging with the results. This shows that the normal VC is not sufficient for sustaining unvoiced MPTs that do not depend on the glottic level. The MPT must be worked in speech therapy to increase the pneumo-phono-articulatory coordination, improving the vocal resistance of voice professionals and dysphonic patients.

One of the limitations of this work is the number of subjects which prevents the generalization of the results. For example, the fact that there are only seven voice professionals among 35 participants does not allow a sufficient investigation. Another limitation is the fact that the data has been collected by different examiners, considering that, despite the standardization of the procedures, it is possible to have interference of aspects related to the evaluator.

From the results of this work, we observe the need for new studies to establish a reference standard for MPT /è/ and MPT /s/, as well as verify the relation between such measures with normal subjects, voice professionals, and different dysphonic groups, also analyzing the gender variable and more age ranges.

\section{CONCLUSION}

This work verified that, as the MPT /é/ value increased, the MPT/s/ value also increased, as well as the VC and vice-versa in both FD and OFD groups, demonstrating the interrelation among these variables.

There was no difference among the variables professional voice use, age, and FD or OFD diagnosis relative to MPT /è/, MPT /s/, and VC. The MPT /è/ values were smaller than the MPT/s/values.

\section{REFERENCES}

1. Awan SN, Novaleski CK, Yingling JR. Test-retest reliability for aerodynamic measures of voice. $\mathrm{J}$ Voice. 2013;27(6):674-84.

2. Joshi A, Watts CR. Phonation Quotient in women: a measure of vocal efficiency using three aerodynamic instruments. J Voice. 2017;31(2):161-7.

3. Pinho SMR. Avaliação e tratamento da voz. In: Pinho SMR (org). Fundamentos em fonoaudiologia: 
tratando os distúrbios da voz. 2. ed. Rio de Janeiro: Guanabara Koogan; 2003. p. 3-40.

4. Englert M, Mesquita LG, Azevedo R. Comparison of methods to extract the maximum phonation duration in individuals without vocal complaints. Rev. CEFAC. 2014;16(5):1615-20.

5. Miglioranzi SL, Cielo CA, Siqueira MA. Vital capacity and maximum phonation times of voiceless /e/ and /s/ in adult women. Rev. CEFAC. 2012;14(1):97-103.

6. Behlau M, Madazio G, Feijó D, Pontes P. Avaliação de voz. In: Behlau M (org). Voz: O livro do especialista vol. I. Rio de Janeiro: Revinter; 2008. p. 85-245.

7. Cielo CA, Gonçalves BFT, Lima JPML, Christmann, MK. Laryngeal disorders, maximum phonation times and vital capacity in women with organofunctional dysphonia. Rev. CEFAC. 2012;14(3):481-8.

8. Cielo CA, Gonçalves BFT, Lima JPML, Christmann MK. Maximum phonation time of /a/, maximun phonation time predicted and respiratory type in adult women without laryngeal disorders. Rev. CEFAC. 2015;17(2):358-63.

9. Irzaldy A, Wiyasihati SI, Purwanto B. Lung vital capacity of choir singers and nonsingers: a comparative Study. J Voice. 2016;30(6):717-20.

10. Ribeiro V, Ribeiro VV, Dassie-Leite AP, ZamberlanAmorin NE, Pereira EC. Desvantagem, queixa vocal e tempo máximo e fonação em mulheres tabagistas. Distúrb Comun. 2014;26(2):213-21.

11. Santos KW, Echeveste SS, Vidor DCG. M. Association between lung function and vocal affections arising from tobacco consumption. Int Arch Otorhinolaryngol. 2014;18(1):11-5.

12. Alves ELO, Coelho CS, Leite APD, Santos RS. Maximum phonation time and its relation to gender, age and lifestyle in healthy elderly. Distúrb Comun. 2015;27(3):530-9.

13. Cardoso NFB, Araújo RC, Palmeira AC, Dias RF, França EET, Andrade FMD et al. Correlação entre o tempo máximo de fonação e a capacidade vital lenta em indivíduos hospitalizados. ASSOBRAFIR Ciência. 2013;4(3):9-17.

14. Johnson AM, Goldfine A. Intrasubject reliability of maximum phonation time. J Voice. 2016;30(6):775. e1-775.e4.

15. Lima DCB, Palmeira AC, Costa EC, Mesquita FOS, Andrade FMD, Correia Junior MAV. Correlation between slow vital capacity and the maximum phonation time in healthy adults. Rev. CEFAC. 2014;16(2):592-7.

16. Cielo CA, Lima JPM, Gonçalves BFT, Christmann $\mathrm{MK}$. The /s/ and /z/ and /e/ and voiceless /e/ ratios. Rev. CEFAC. 2013;15(5):1308-15.

17. Beber BC, Cielo CA, Siqueira MA. Lesões de borda de pregas vocais e tempos máximos de fonação. Rev. CEFAC. 2009;11(1):134-41.

18. Behlau M, Madazio G, Oliveira G. Functional dysphonia: strategies to improve patient outcomes. Patient Relat Outcome Meas. 2015;6(1):243-53.

19. López JM, Catena A, Montes A, Castillo EM. Effectiveness of a short voice training program for teachers: a preliminary study. $J$ Voice. 2017;31(6):697-706.

20. Bernhard R, Nusseck M, Spahn C. Effectiveness of a voice training program for student teachers on vocal health. J Voice. 2016; 30(4):452-9.

21. Mohseni R, Sandoughdar N. Survey of voice acoustic parameters in iranian female teachers. $J$ Voice. 2016;30(4):507.e1-507.e5.

22. Adrián JA, Rodríguez-Parra MJ. Evaluación del tratamiento logopédico en la rehabilitación de la disfonía en adultos: seguimiento de los efectos grupales y de las variaciones individuales. Rev Logop Foniatr Audiol. 2015;35(1):17-29.

23. Pinar D, Cincik H, Erkul E, Gungor A. Investigating the effects of smoking on young adult male voice by using multidimensional methods. J Voice. 2016;30(6):721-5.

24. Miglioranzi SL, Cielo CA, Siqueira MA. Relação entre capacidade vital, tempos máximos de fonação de /e/ emitido de forma áfona, de /s/ e estatura em mulheres adultas. Rev. CEFAC. 2011;13(6):1066-72.

25. Rossi DC, Munhoz DF, Nogueira CR, Oliveira TCM, Britto ATBO. Relação do pico de fluxo expiratório com o tempo de fonação em pacientes asmáticos. Rev. CEFAC. 2006;8(4):509-17.

26. Pereira ERBN, Tavares ELM, Martins RHG. Voice disorders in teachers: clinical, videolaryngoscopical, and vocal aspects. J Voice. 2015;29(5):564-71.

27. Aghajanzadeh M, Darouie A, Dabirmoghaddam $P$, Salehi A, Rahgozar M. The relationship between the aerodynamic parameters of voice and perceptual 
evaluation in the iranian population with or without voice disorders. J Voice. 2017;31(2):250 e9-e15.

28. Pedrosa V, Pontes A, Pontes P, Behlau M, Peccin $\mathrm{SM}$. The effectiveness of the comprehensive voice rehabilitation program compared with the vocal function exercises method in behavioral dysphonia: a randomized clinical trial. J Voice. 2016;30(3):377. e11-e19. 